\title{
The impact factor of Plant and Soil reached a record of 3.235
}

\author{
Hans Lambers
}

Received: 5 August 2014 / Accepted: 12 August 2014 / Published online: 16 August 2014

(C) Springer International Publishing Switzerland 2014

Many of you will have noticed that the Impact Factor of Plant and Soil has risen steadily over the past decade and that it is now 3.235. It ranks third in a total of 33 journals in the category 'Soil Science', or second if the '5-year Impact Factor' is used or if a correction is made for 'Journal Self Cites'. Some journals are very keen on their authors citing recent papers published in their own journal to boost their Impact Factor which is a practice Plant and Soil does not support. Other journals boost their Impact Factor by publishing reviews at the beginning of the year, aiming to maximise citations in the subsequent 2 years. Plant and Soil publishes its prestigious Marschner Reviews, which are important for our readers, but citations to these reviews represent only $3 \%$ of the total citations. What this shows is that the Impact Factor of Plant and Soil is real, and not generated by a few tricks that are common in the trade.

In the much larger category of 'Agronomy', Plant and Soil ranks seventh in a total of 107 journals, and in the even larger category of 'Plant Sciences', it ranks 32 among 196 journals. It is not (yet) ranked in 'Ecology', but had it been ranked there, it would be at very respectable position 38 among 141 journals (if Plant and Soil had already been added to the current list of 140). In recent years, an increasing number of papers with a focus on soil and plant ecology have been published in

Responsible Editor: Hans Lambers.

H. Lambers $(\bowtie)$

The University of Western Australia,

Crawley, Perth, WA, Australia

e-mail: hans.lambers@uwa.edu.au
Plant and Soil, and the new Impact Factor makes it a very attractive journal for many ecologists, who obviously frequently cite papers from Plant and Soil.

Plant and Soil is a firmly established international journal for research that enhances our mechanistic understanding of plant-soil interactions, appealing to ecologists, plant scientists, soil scientists and agronomists. We wish to remain at the forefront of that focused area, rather than cover all aspects of plant and soil science, and make further improvements wherever possible. Our Board of Section Editors and Consulting Editors is continually renewed to cover major areas, including molecular aspects of plant-microbe interactions. When checking the list of our Editors, you will notice that we are well prepared to deal with manuscripts on root physiology, soil ecology, soil physics, soil biochemistry, symbiotic and pathogenic interactions, rhizosphere biology, root biochemistry and effects of global change on soil-plant interactions. We also welcome manuscripts with a strong anatomical or modelling component.

Plant and Soil continues to publish prestigious Marschner Reviews (by invitation only) and other reviews, which cover areas of interest to our readers. We also offer the opportunity of publishing 'commentaries' as well as 'opinion papers'. To emphasise our scope and policy, we will continue to place a photograph on the front cover of each issue, pertaining to an important article preferably in that issue of Plant and Soil. We encourage authors to submit illustrative material with their manuscripts.

Major developments are to be expected in the interface of plant and soil sciences, often referred to as 'the 
new frontier'. Plant and Soil seeks to report on these by publishing original and review papers of a very high standard. With the continued help of our invaluable Consulting Editors and anonymous reviewers and of the professional staff at Springer's offices, the Editorial Board of Plant and Soil is confident that the journal will continue to play a significant role for our readers and authors. 